University of Nebraska - Lincoln

DigitalCommons@University of Nebraska - Lincoln

January 2007

\title{
SUBADULT FEMALE EXPERIENCE DOES NOT INFLUENCE SPECIES RECOGNITION IN THE WOLF SPIDER SCHIZOCOSA UETZI STRATTON 1997
}

Eileen Hebets

University of Nebraska - Lincoln, ehebets2@unl.edu

Follow this and additional works at: https://digitalcommons.unl.edu/bioscihebets

Part of the Behavior and Ethology Commons

Hebets, Eileen, "SUBADULT FEMALE EXPERIENCE DOES NOT INFLUENCE SPECIES RECOGNITION IN THE WOLF SPIDER SCHIZOCOSA UETZI STRATTON 1997" (2007). Eileen Hebets Publications. 10.

https://digitalcommons.unl.edu/bioscihebets/10

This Article is brought to you for free and open access by the Papers in the Biological Sciences at DigitalCommons@University of Nebraska - Lincoln. It has been accepted for inclusion in Eileen Hebets Publications by an authorized administrator of DigitalCommons@University of Nebraska - Lincoln. 


\title{
SUBADULT FEMALE EXPERIENCE DOES NOT INFLUENCE SPECIES RECOGNITION IN THE WOLF SPIDER SCHIZOCOSA UETZI STRATTON 1997
}

\author{
Eileen A. Hebets: School of Biological Sciences, University of Nebraska, Lincoln, \\ Nebraska 68588, USA. E-mail: ehebets2@unl.edu
}

\begin{abstract}
In many vertebrate systems, early experience has been linked to the learning of speciesspecific traits that are subsequently assessed during mate choice, thus ensuring conspecific matings. In invertebrate systems, however, early experience was not thought to play a role in mate choice until a recent study using Schizocosa uetzi Stratton 1997 wolf spiders demonstrated that females mate more readily with males of a familiar versus unfamiliar phenotype. The function of early mate choice learning in this system is not yet known, but a role in learning species-specific traits seems unlikely. In northwestern Mississippi, S. uetzi is found sympatrically with S. stridulans Stratton 1991, which matures slightly earlier in the season. If $S$. uetzi early mate choice learning functions in learning species-specific traits used in mate choice, as is often the case in vertebrate systems, then subadult female exposure to heterospecifics ( $S$. stridulans) could result in heterospecific matings. Here, I exposed subadult $S$. uetzi females to courtship advances from mature males of either $S$. uetzi (conspecifics) or S. stridulans (heterospecifics) in order to test a species-specific mate choice learning function. Previously exposed females were paired with a mature male of the same, or the opposite, species as their exposure male. As expected, the results do not support a species-specific mate choice learning function. Previously exposed females mated significantly more with conspecific males regardless of their exposure treatment, as did unexposed females. The highest premating sexual cannibalism rates occurred in heterospecific mate choice trials regardless of the exposure treatment, and exposed females were more likely to cannibalize males than unexposed females. While previous results demonstrate that subadult experience influences conspecific mate choice, a species recognition template seems to exist that is independent of the influence of early experience. The potential influence of multimodal signal interactions on conspecific mate choice learning is discussed.
\end{abstract}

Keywords: Experience, Araneae, Lycosidae, species recognition, mate choice, cannibalism

Conspecific mating preferences have traditionally been thought to be under genetic control (sensu Fisher 1958). However, considerable evidence has been building, suggesting the importance of environmentally and socially influenced mating preferences (for reviews see Dugatkin 1996a; Brooks 1998; Irwin \& Price 1999; Owens et al. 1999; Freeberg 2000; White 2004). For example, predation risk has been shown to alter female guppy preferences for male traits (Gong \& Gibson 1996). Female satin bower birds of different ages utilize different criteria in choosing males (Coleman et al. 2004). Female guppies and Japanese quail alter their mate choice decisions based on the mate choice of other females (Dugatkin 1992a,1992b,1996b; Galef \& White 2000; White \& Galef 2000; White 2004). Sexual imprinting has even been suggested to be the rule rather than the exception for the origin of mating preferences in birds (ten Cate 1993).
While virtually all of the examples involving the influence of early experience on subsequent mate choice have traditionally involved vertebrates, a recent study provides one of the first examples of socially influenced mating preferences in an invertebrate. After exposure to mature males as subadults, adult female wolf spiders (Schizocosa uetzi Stratton 1997) were shown to mate significantly more with males of a familiar versus unfamiliar phenotype (Hebets 2003). Furthermore, as adults, these exposed females were more likely to cannibalize males of an unfamiliar phenotype (Hebets 2003). Due to the potential for sexual cannibalism in this system, the selection pressure placed on mating behavior is extremely high. As such, social interactions that influence the origin or maintenance of female mating preferences could potentially play an important role in the subsequent evolution of male secondary sexual traits. 
The finding that the adult mate choice of $S$. uetzi females is dependent on subadult female experience is not only important because it expands the probable importance of socially influenced mate choice to include non-vertebrate groups, but it also represents a life stage (subadult females) during which mate choice learning has not been frequently explored. Most studies of mate choice learning focus on either a period very early in life or on experiences females have as adults. Sexual imprinting, for example, is typically restricted to a critical period early in life and is frequently argued to be a means by which young birds learn species-specific characteristics (Bateson 1966; Immelmann 1975; Irwin \& Price 1999). In contrast, mate choice copying, or imitation, involves already mature females copying the mate choice of other mature females and is often thought of as a means of avoiding costs associated with mate choice (i.e., search time and costs of assessing mates) (see review White 2004). If sexual imprinting functions to insure conspecific adult mate choice, it follows that the influences are limited to a critical period early in life in taxa with parental care; both factors that increase the likelihood that an individual will imprint on its parents. In the case of mate choice copying, as an adult that is putatively ready to mate, imitating the choices of others is also logical as it could potentially cut down on costs and time associated with choosing a mate independently. However, in the case of the wolf spider $S$. uet$z i$, exposure experiments demonstrated an effect of subadult experience on adult mate choice. This experience was gained during a female's penultimate life stage. Due to the short lifespan of these spiders $(\sim 1 \mathrm{yr})$ and the lack of parental care, it is impossible for subadult females in the field to gain experience with parental phenotypes. Furthermore, an effect of experience was demonstrated before females were mature, hence, prior to their ability to mate, thus ruling out mate choice copying. The question then arises regarding the potential influence and/or function of subadult mate choice learning on subsequent adult mate choice in natural populations of the wolf spider $S$. uetzi.

While innate recognition of species specific language and song has certainly been demonstrated, early experience with siblings or parents in many species is crucial for learning species-specific characteristics (Laland 1994; Irwin \& Price 1999; ten Cate \& Vos 1999). In several studies involving cross-fostering experiments with birds as well as mammals, sexual imprinting has been shown to lead to heterospecific mate choice (Kendrick et al. 1998; Penn \& Potts 1998; Slagsvold et al. 2002). Examples involving early learning of species-specific characteristics tend to involve species with parental care. Based on the lack of parental care in wolf spiders as well as the high degree of sympatry among Schizocosa species in the southeast (personal observation), it seems unlikely that subadult female mate choice learning in $S$. uetzi functions to insure specific-specific adult mate choice. Since species recognition requires that only one signal variant be recognized by all members of one species, species recognition mechanisms are often hard-wired (Bradbury \& Vehrencamp 1998). Previous studies exploring other wolf spider species, including members of the genus Schizocosa, demonstrate a lack of hybridization between closely related species (Stratton \& Uetz 1981, 1986; Stratton 1983; Costa \& Francescoli 1991). However, forced copulations between closely related species produced viable offspring, suggesting a low cost for heterospecific matings (Stratton \& Uetz 1981). Regardless, prior heterospecific mate choice studies of spiders involved naïve, inexperienced females. The potential for subadult female experience to influence speciesspecific mate choice recognition has not yet been examined in spiders and before other hypotheses regarding the function of subadult female mate choice learning in $S$. uetzi can be explored, one must rule out the possibility of species-specific mate choice learning.

Schizocosa uetzi overlaps, at least partially in time and space, with several other species of Schizocosa, most notably S. stridulans Stratton 1991 (pers. obs.) with which is it closely related (Stratton 1991, 1997, 2005; Vink \& Hebets unpublished data). Laboratory studies using $S$. uetzi and S. stridulans individuals suggest that females of each species will occasionally display receptively to heterospecific males under conditions where the background levels of noise in both the visual and seismic signaling environments are manipulated (Hebets unpublished data). Furthermore, the male courtship behavior and morphology of $S$. uetzi and $S$. stridulans is very 


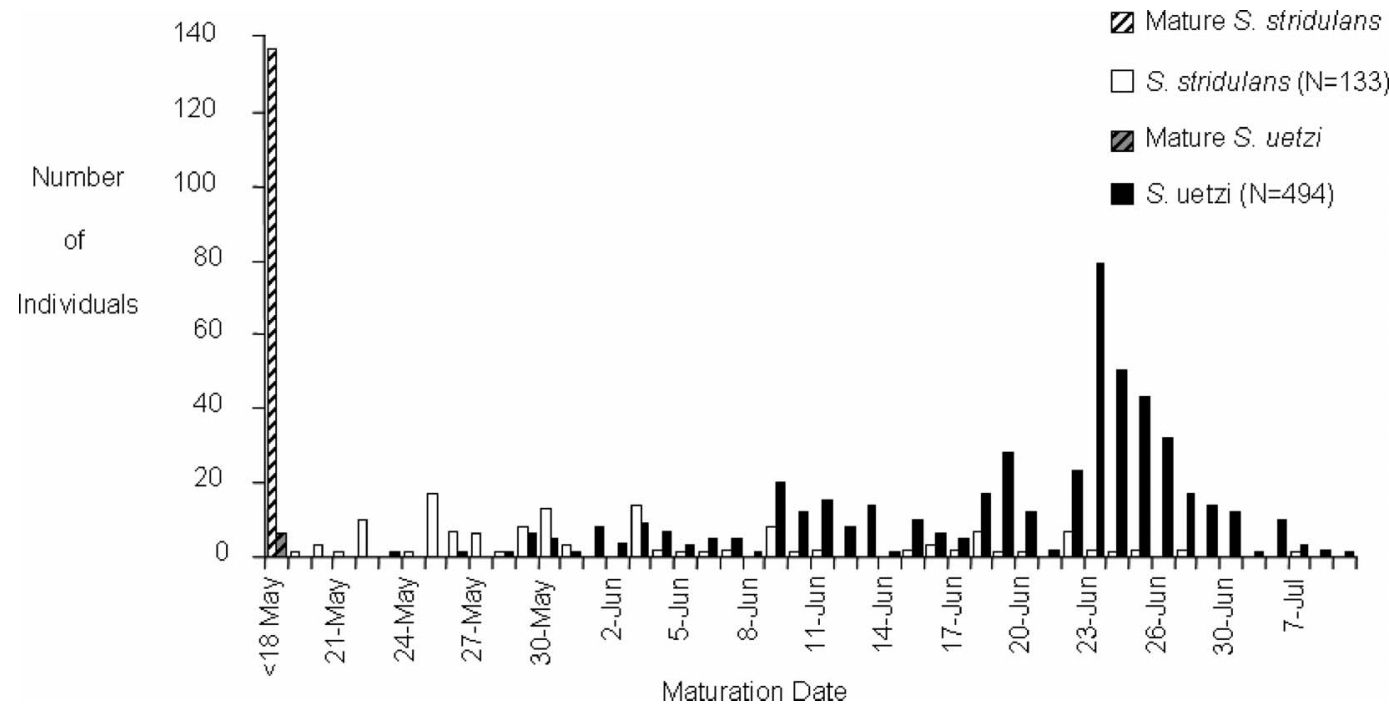

Figure 1.-Maturation dates (three seasons) for S. stridulans and S. uetzi (2001-2003). Prior to the 19th of May, $137 \mathrm{~S}$. stridulans and $6 \mathrm{~S}$. uetzi were colleted from the field already mature, indicating the slightly earlier maturation time of $S$. stridulans. All other data represent the dates of maturation in the laboratory. In all years, many already mature individuals were observed but not collected and, thus, this graph is a conservative estimate of species overlap.

similar and, without examination under a microscope, it is impossible to tell females of the two species apart. If subadult female mate choice learning functions to insure subsequent conspecific matings in $S$. uetzi, then the prevalence of heterospecific males (S. stridulans) in the system could result in adult mate choice "mistakes," or misidentifications.

Here I explore the possibility that early experience provides an opportunity for subadult females to learn species-specific characteristics by examining the potential influence of subadult experience on heterospecific mate choice in the wolf spider $S$. uetzi. To test the hypothesis that early experience functions in species-specific mate choice learning, I exposed subadult $S$. uetzi females to either conspecific or heterospecific mature males. On their maturation, I then paired these previously exposed females with a mature male of either the same or the opposite exposure treatment for mate choice trials. As a control, a group of unexposed females were paired with conspecific or heterospecific mature males upon maturation.

\section{METHODS}

Species.-Schizocosa uetzi and S. stridulans are sister species (Vink \& Hebets unpub- lished data) found sympatrically in the deciduous forests of northwestern Mississippi, USA. They are similar in size and are often difficult to distinguish. A combination of $3 \mathrm{yr}$ worth of collection data (2001-2003) reveals that while the peak maturation time for $S$. stridulans is in late May as compared to late June for $S$. uetzi, there is still significant overlap in maturation times and mature individuals of both species can be present simultaneously in the field (Fig. 1). Due to their morphological similarities as well as their potential overlap in both space and time, $S$. stridulans males were used as the heterospecific species in this experiment. Subadult $S$. uetzi and $S$. stridulans of both sexes were collected from sites near Oxford, Mississippi, USA in May 2003 and brought back to the laboratory where they were housed individually in $6 \times 6 \times 8 \mathrm{~cm}$ AMAC plastic products boxes. Individuals were fed 2-3 crickets once a week, were provided with a constant source of water, and were kept on a 12L:12D cycle. All cages had opaque sides to insure visual isolation. Spiders were checked at least every other day for molts and the maturation date for all individuals was recorded. On completion of all experiments, I examined preserved females un- 
der a dissecting scope to insure species identity. I used $\sim 15$ known $S$. stridulans females and $\sim 15$ known $S$. uetzi females from prior laboratory matings (Hebets 2002) in order to establish the within-species variation in epigynal characters. Using known individuals of each species as a comparison, I determined the species identity of every female used in this experiment.

Exposure trials.-Subadult $S$. uetzi females were randomly assigned to either a conspecific (S. uetzi) or heterospecific (S. stridulans) male treatment. During their penultimate stage, subadult females were placed in an arena with a mature male of their assigned treatment for 30 min every other day until their final maturation molts. Females were never exposed to the same male twice. All experimental arenas were $8.73 \times 8.73 \times 11.27 \mathrm{~cm}$ Amac Plastic Product clear boxes and had a single piece of filter paper lining the bottom. The night prior to both exposure trials and mate choice trials, a mature $S$. uetzi female was placed on the filter paper and left overnight. Mature females deposit silk along with an associated pheromone that will elicit courtship behavior in mature males even in the absence of a female. Once courtship is elicited, males will direct their courtship towards any spider present, providing the subadult females with experience with either conspecific or heterospecific courting adult males. Only two $S$. stridulans males were used twice during the exposure trials, but not with the same female, and all other males were used only once ( $S$. stridulans, $n=29$; S. uetzi, $n=33$ ).

Mate choice trials.- Once the exposed females molted to maturity, they remained isolated in their individual cages until the mate choice trials. Mate choice trials of exposed females were conducted 11-20 d (= days) after their final maturation molts since mature females are not receptive immediately after maturation. In adult mate choice trials, females were randomly assigned either to males from the same treatment type as their exposure trials, or the opposite treatment type. Each female was paired with only one test male, resulting in four treatments: heterospecific exposure/heterospecific mate choice; heterospecific exposure/conspecific mate choice; conspecific exposure/heterospecific mate choice; and conspecific exposure/conspecific mate choice. Females were placed in the same arenas as were used for the exposure trials and after 2 min of acclimation time, a male was introduced. All arenas were swabbed with alcohol in between trials. Mate choice trials lasted $30 \mathrm{~min}$ and trials were scored for the presence/absence of copulation, the latency to copulation (duration of time from beginning of trial until the male mount), and the presence/absence of sexual cannibalism. A total of 16 unexposed $S$. stridulans males were used, with two individuals used twice, and a total of 18 unexposed $S$. uetzi males were used only once each. Males were randomly assigned to trials.

Unexposed females. - The mate choice of unexposed females was also assessed in this study. Thirty-six subadult $S$. uetzi females were collected from the field and were placed in individual cages where they remained isolated until at least $11 \mathrm{~d}$ after their final maturation molts. These unexposed females were randomly assigned either a heterospecific or conspecific male treatment and were subjected to mate choice trials in the same manner as were the exposed females. Each unexposed female was only used once with one male. Voucher specimens are deposited in the University of Nebraska State Museum, Lincoln, Nebraska, USA.

\section{RESULTS}

Sixty-four subadult $S$. uetzi females gained experience with either heterospecific or conspecific mature males. Mating frequency was dependent on the treatment $\left(X^{2}=23.46, P<\right.$ $0.001, d f=3$, Fig. 2). Exposed females mated significantly more with conspecific males versus heterospecific males $\left(X^{2}=10.85, P=\right.$ $0.001, d f=1$, Fig. 2 ), but the type of male a female was exposed to did not influence mating frequency $\left(X^{2}=2.23, d f=1\right.$, ns). This analysis includes all females.

While the courtship behavior of $S$. uetzi and $S$. stridulans males differ, their courtship effort was similar (S. stridulans $84 \%$ courted, $S$. uetzi $91 \%$ courted; $X^{2}=0.73$, ns). When I only analyzed the females for which males were known to engage in courtship during the exposure trials, the results were similar to analyses including all females $\left(X^{2}=21.93, P\right.$ $<0.0001, d f=3 ; S$. stridulans $/ S$. stridulans $n=16,0 \%$ mated; S. stridulans $/ S$. uetzi $n$ $=17,53 \%$ mated; S. uetzi/S. stridulans $n=$ 13, $23 \%$ mated; S. uetzi/S. uetzi $n=16,63 \%$ 


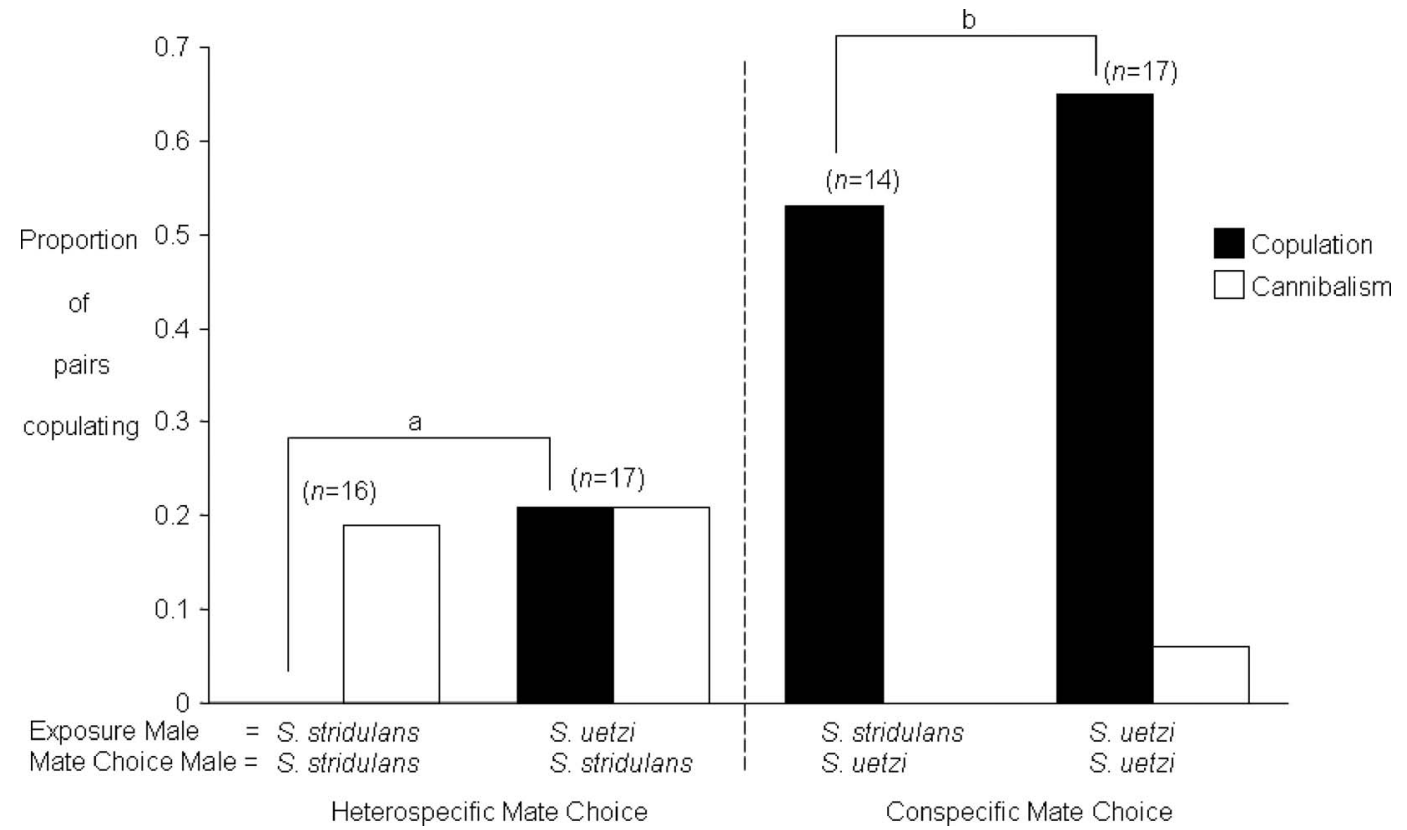

Figure 2.-Responses of female $S$. uetzi as measured by proportion of pairs copulating or proportion of pairs ending in cannibalism. Female $S$. uetzi were exposed as subadults to either heterspecific males (S. stridulans) or conspecific males $(S$. uetzi). As adults, these females were paired with either the same, or the opposite, male type as their prior exposure (heterospecific vs conspecific male) and were given an opportunity to mate. Mating frequency was dependent on treatment and pairs mated more frequently in conspecific mate choice trials versus heterospecific mate choice trials, regardless of the exposure treatment. Different letters indicate significant differences.

mated). Cannibalism frequency did not depend on the treatment regardless of whether all females are included $\left(X^{2}=6.6, d f=3\right.$, $\mathrm{ns})$, or when only females that were known to have been exposed to male courtship during the exposure trials were analyzed $\left(X^{2}=5.34\right.$, $d f=3$, ns).

Sixty-one percent of the subadult females were exposed to more than one courting male. The maximum number of times a female was exposed was six. The number of times a female was exposed was independent of treatment $\left(F_{3,61}=1.04\right.$, ns; $S$. stridulans $/ S$. stridulans mean $\pm \mathrm{SE}=2.13 \pm 0.34 ; S$. stridulans/S. uetzi mean $\pm \mathrm{SE}=2.41 \pm 0.33$; S. uetzi/S. stridulans mean $\pm \mathrm{SE}=1.93 \pm$ 0.36; S. uetzi/S. uetzi mean $\pm \mathrm{SE}=1.94 \pm$ 0.33 ). The number of times a female was exposed did not influence her likelihood to copulate $\left(F_{5,42}=1.37, \mathrm{~ns}\right.$; treatment: $F_{3}=1.04$, $P=0.36$; copulate: $F_{1}=0.009, P=0.92$; treatment x copulate: $\left.F_{3}=2.41, P=0.10\right)$, or her likelihood to cannibalize $\left(F_{5,41}=1.42\right.$, ns; treatment: $F_{3}=0.48$, ns; cannibalize: $F_{1}$
$=0.55, P=0.58$; treatment $\mathrm{x}$ copulate: $F_{3}=$ $1.87, \mathrm{~ns})$.

Unexposed females mated significantly more with conspecific males than with heterospecific males (conspecific males $n=18$, $39 \%$ copulated; heterospecific males $n=18$, $11 \%$ mated; $X^{2}=3.87, P=0.049$, see Fig. 3 ), and there were no cannibalism events with unexposed females. The latency to copulation did not differ among any of the treatments in which copulation occurred $\left(F_{4,27}=0.39\right.$, ns; $S$. stridulans $/ S$. uetzi $n=9$, mean $\pm \mathrm{SE}=$ $9.88 \pm 2.5 ; S$. uetzi/S. stridulans $n=3$, mean $\pm \mathrm{SE}=10.59 \pm 4.3 ; S$. uetzi/S. uetzi $n=11$, mean $\pm \mathrm{SE}=10.10 \pm 2.3$; unexposed/S. stridulans $n=2$, mean $\pm \mathrm{SE}=12.47 \pm 5.3$; unexposed $/ S$. uetzi $n=7$, mean $\pm \mathrm{SE}=6.58$ \pm 2.8 ).

When exposed and unexposed trials are combined, mating frequency is dependent on treatment $\left(X^{2}=28.63, P<0.0001\right)$ with mating frequencies significantly higher when the treatments involve $S$. uetzi as the mate choice male (i.e., a conspecific) as opposed to $S$. stri- 


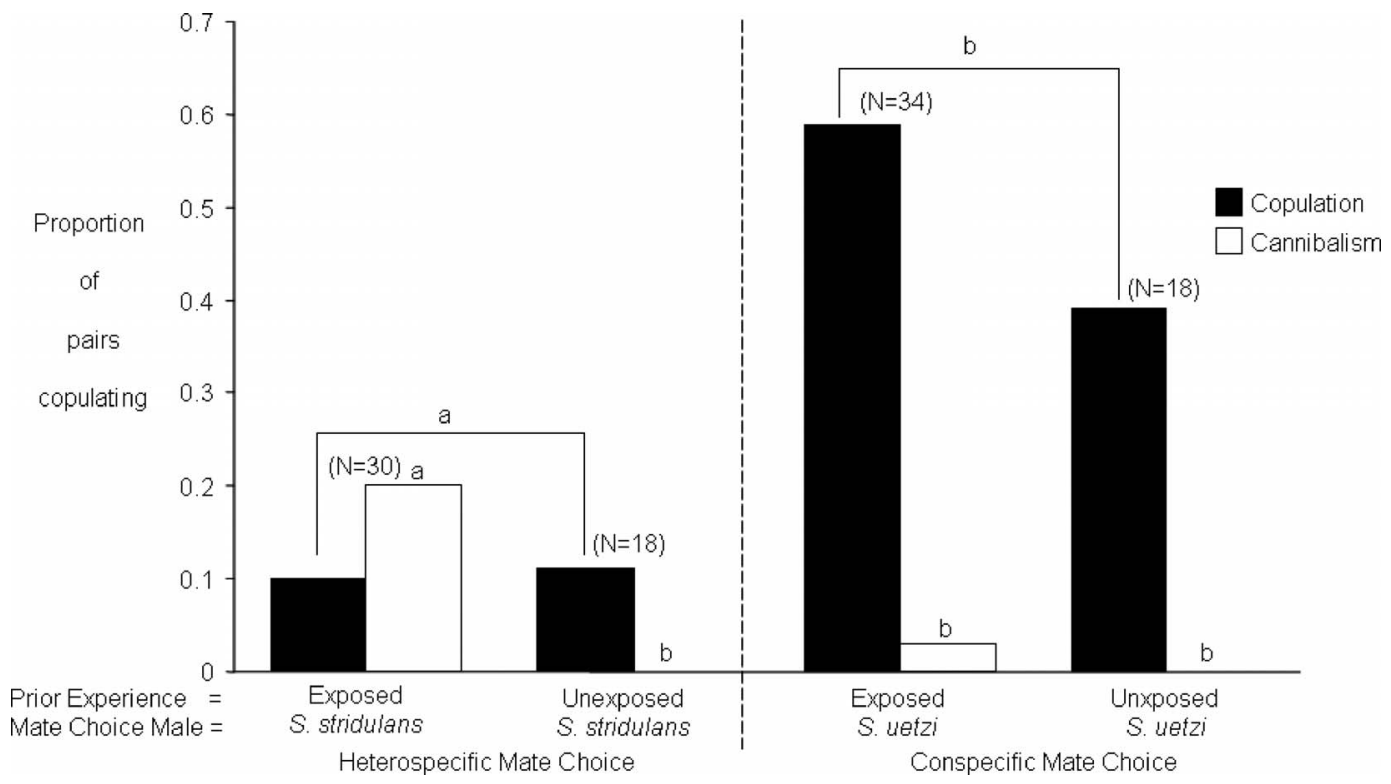

Figure 3.-Schizocosa uetzi female responses as measured by proportion of pairs copulating or proportion of pairs ending in cannibalism. Schizocosa uetzi females were either exposed to a mature male as a subadult (includes all exposures regardless of male type) or were unexposed (no known prior exposure to any mature male). As adults, females were paired with either a heterospecific male (S. stridulans) or a conspecific male $(S$. uetzi) and were given an opportunity to mate. Regardless of whether females were exposed or not, they mated significantly more with conspecific males than heterospecific males. Cannibalism rates were significantly higher with previously exposed females paired with heterospecific mate choice males compared to all other categories.

dulans (i.e., a heterospecific). An analysis that ignores the exposure males and lumps all similar mate choice trials together results in this same pattern: mating frequency is significantly higher with conspecific versus heterospecific mate choice trials $\left(X^{2}=23.18, P<\right.$ 0.0001 , Fig. 3). Precopulatory cannibalism rate is also dependent on treatment with exposed females paired with $S$. stridulans (heterospecific) having higher cannibalism rates than any other treatment category $\left(X^{2}=\right.$ 11.68, $P=0.009$; Fig. 3).

In a comparison that combined all exposed females verses unexposed females, mating frequency does not depend on the presence/ absence of exposure $\left(X^{2}=1.3\right.$, ns, Fig. 4). However, cannibalism frequency does depend on the presence/absence of exposure, with more cannibalisms occurring with the exposed females versus the unexposed females $\left(X^{2}=\right.$ $6.5, P=0.01$, Fig. 4). When comparing only the subset of females that were exposed to $S$. uetzi males and paired with $S$. uetzi males for mate choice trials $(S$. uetzi/S. uetzi) to unex- posed females paired with $S$. uetzi males, there is no statistical difference between exposed and unexposed females with respect to copulation frequency $\left(X^{2}=2.4\right.$, ns, $P=0.12$, Fig. $5)$.

\section{DISCUSSION}

While several studies involving both birds and mammals have demonstrated that early experience with heterospecifics can lead to heterospecific mating preferences later in life (Kendrick et al. 1998; Penn \& Potts 1998; Slagsvold et al. 2002), this same effect is not seen in $S$. uetzi wolf spiders. Here, I confirm the expectation that a subadult female's experience with only heterospecific males does not lead to heterospecific mate choice preferences. Even when exposed to heterospecific males as subadults, $S$. uetzi females preferred to mate with conspecific males. This preference for conspecific males was present in both exposed as well as unexposed females. These results suggest that a strong species recognition template is in place for $S$. uetzi and that 


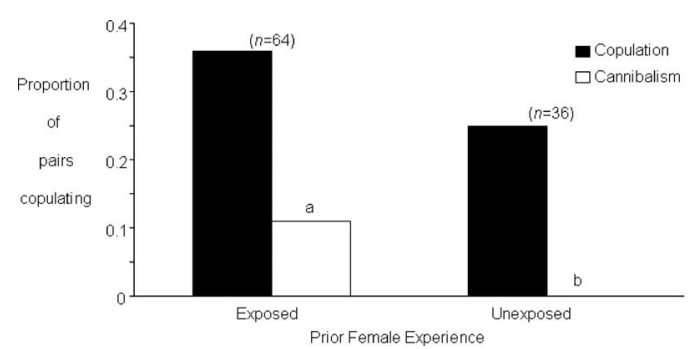

Figure 4.- The effect of exposure on the likelihood of $S$. uetzi females to copulate and cannibalize. Exposed females tend to copulate more frequently than unexposed females, although this is not significant. Exposed females are however, more likely to cannibalize a male than unexposed females.

subadult female mate choice learning does not function to insure subsequent conspecific recognition.

Nevertheless, while females significantly preferred conspecific males, five of the females tested did mate with heterospecific, $S$. stridulans males. Unfortunately, the species identity of these five individuals could not be confirmed. Schizocosa stridulans and S. uetzi are extremely similar and it is particularly difficult to tell females apart and virtually impossible without examining their genitalia. Unfortunately, the preserved bodies of these females could not be located. Thus, without a close examination of these five females, I cannot be certain that they were not $S$. stridulans females and thus cannot confirm the existence of any heterospecific matings between these two species. The species identity of all other females was confirmed by examining their genitalia under a dissecting scope.

While exposure itself did not significantly influence mating frequency, Figures 4 and 5 illustrate a compelling trend suggesting that exposed females are more likely to mate than unexposed females. This same trend, suggesting that experience leads to an increased likelihood to mate, was also demonstrated in the original study exploring the influence of early experience on adult mate choice in $S$. uetzi (Hebets 2003). The potential influence of early experience on the likelihood to mate is certainly intriguing and I believe that future studies that control for female age across treatments and involve larger samples sizes of unexposed females will be successful in further illuminating this pattern.

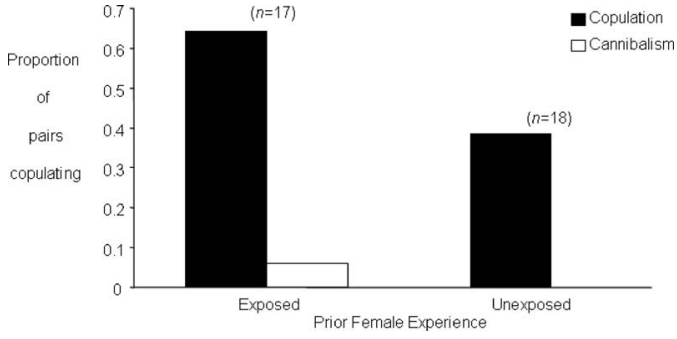

Figure 5.-The effect of exposure on the likelihood of $S$. uetzi females to mate with or to cannibalize conspecific males, comparing those previously exposed to a conspecific male vs those with no prior experience with any mature male (exposure/mate choice $=S$. uetzi/S. uetzi vs unexposed/ $S$. uetzi). Exposed females tend to mate more frequently than unexposed females, but the difference is not significant.

Although exposure itself did not significantly influence mating frequency, it did influence cannibalism frequency. Compared to unexposed females, females that were exposed to courtship advances from mature males as subadults were more likely to cannibalize males in subsequent adult encounters. Specifically, exposed females were more likely to cannibalize heterospecific males, regardless of their exposure treatment. Exposed females were more likely to cannibalize males than unexposed females in the Hebets (2003) study as well $\left(X^{2}=5.55, P=0.02\right)$. Interestingly, in both Hebets (2003) and the present study, unexposed females never engaged in pre-copulatory sexual cannibalism. In both studies, since females were collected from the field as early penultimates, the mate choice trials may have represented the first time that these unexposed females experienced courtship advances from mature males, and therefore, represented the first time females acquired knowledge of the presence of mature males. This knowledge, or lack thereof, regarding the existence of other males may influence a female's readiness to cannibalize. Unexposed females may have a higher perceived cost associated with a missed detection (sensu Wiley 1994), or misidentification, than exposed females, and thus may be more cautious in their distinction between conspecific versus heterospecific males (or between mate and meal). Examining the influence of experience on a female's perceived costs and ben- 
efits of mate choice/cannibalism represents an intriguing direction for future research.

Until now, the two most common functions of the influence of early experience on subsequent mate choice have involved (1) insuring conspecific mate choice (often via sexual imprinting) or (2) reducing the costs associated with searching and assessing potential mates (via mate-choice copying). This study suggests that neither function is generally applicable to the subadult mate choice learning of $S$. uetzi. However, the learning of speciesspecific visual characteristics remains a possibility. Results from Hebets (2003) suggest that subadult female $S$. uetzi specifically learn visual characteristics of conspecific mature males, which are subsequently used in adult mate choice decisions (i.e., visual learning). While the previous study involved experimentally manipulating visual secondary sexual traits of males and subsequently assessing female mate choice, it did not rigidly control for effects of odor learning (Hebets 2003). Nonetheless, since spiders are not known to possess sensory structures characteristic of olfactory perception (Foelix 1996), and since mate choice happens before any male-female contact that could lead to the potential perception of contact chemicals, visual learning remains the most plausible explanation. However, $S$. uetzi males, along with many other species in the genus, use seismic signals in addition to visual signals in their courtship displays (multimodal signaling: Rovner 1975; Stratton \& Uetz 1981, 1983; Stratton \& Uetz 1983; Barth 1986; Hebets \& Uetz 1999; Uetz \& Roberts 2002; Hebets 2005). The seismic signals appear to be species specific (Stratton \& Uetz 1981; Elias \& Hebets unpublished data) and are thought to be ancestral in this genus. Previous work assessing the function of multimodal signaling in $S$. uetzi has already demonstrated that the visual and seismic signals interact such that females respond differently to varying visual signals only in the presence of a seismic signal (Hebets 2005). Thus, the seismic signal appears to focus a female's attention on the visual signal.

In light of the attention-altering hypothesis of multimodal signaling in $S$. uetzi, results of the present study are consistent with the notion that the seismic signal of $S$. uetzi male courtship may function as a password for species recognition (sensu Hauber et al. 2001).
Females may learn conspecific visual male traits only in the presence of a conspecific seismic courtship signal. Since all of the exposure trials included seismic signals, females may have only engaged in subadult mate choice learning of visual signals in the presence of a conspecific seismic signal, which meant learning only the visual morphology of a conspecific male. Experiments involving seismic exposure to conspecific male courtship signals simultaneous with visual exposure to heterospecific male courtship signals would further elucidate this possibility. Crossmodal signal interactions influencing learning have already been demonstrated in several taxa. For example, the presence of sound has been shown to significantly increase the speed with which chicks can learn to avoid unrewarding visual stimuli (Rowe 2002). A whistle has been shown to serve as a cue for song learning in the white-crowned sparrow (Soha \& Marler 2000). In a similar fashion, the presence of a conspecific seismic signal may facilitate a subadult female's learning of visual characteristics in S. uetzi.

In summary, this study demonstrates that subadult female experience does not influence general adult species-specific mate recognition in the wolf spider $S$. uetzi. Instead, results suggest that there is a species recognition template in place that is independent of the effect of early experience. This species recognition template likely involves the seismic courtship signal. In conclusion, a potential adaptive value associated with subadult female learning remains unknown, but, if found, it will likely prove to be novel among the known functions of social influences of mate choice.

\section{ACKNOWLEDGMENTS}

I would like to thank G. Stratton and P. Miller for help in collecting spiders and in providing food, lodging, and insightful conversations during collecting trips. K. Cuasay and D. Nee helped in exposure as well as mate choice trials. D. Elias, D. Papaj, R. Hoy, N. VanderSal, K. Fowler-Finn, A. Spence, and J. Storz all provided useful comments and suggestions. The work was conducted in the lab of R. Hoy and was funded by an NIH training grant to the Department of Neurobiology and Behavior, Cornell University, Ithaca, New York. 


\section{LITERATURE CITED}

Barth, F.G. 1986. Vibration sense and vibratory umwelt of spiders. Naturwissenschaften 73:519530 .

Bateson, P. 1966. The characteristics and context of imprinting. Biological Reviews 41:177-220.

Bradbury, J.W. \& S.L. Vehrencamp. 1998. Principles of Animal Communication. Sinauer Associates, Sunderland, Massachusetts. 882 pp.

Brooks, R. 1998. The importance of mate copying and cultural inheritance of mating preferences. Trends in Ecology \& Evolution 13:45-46.

Coleman, S.W., G.L Patricelli \& G. Borgia. 2004. Variable female preferences drive complex male displays. Nature 428:742-745.

Costa, F.G. \& G. Francescoli. 1991. Analyse expérimentale de l'isolement reproductif entre deux espèces jumelles et sympatriques d'araignées: le Lycosa thorelli (Keyserling) et le Lycosa carbonelli Costa et Capocasale. Canadian Journal of Zoology-Revue Canadienne De Zoologie 69: 1768-1776.

Dugatkin, L.A. 1992a. Reversal of female mate choice by copying. Proceedings of the Royal Society of London Series B-Biological Sciences 249:179-184.

Dugatkin, L.A. 1992b. Sexual selection and imitation: females copy the mate choice of others. American Naturalist 139:1384-1389.

Dugatkin, L.A. 1996a. Copying and mate choice. Pp. 85-106. In Social Learning in Animals: the Roots of Culture (C.M. Heyes \& B.G. Galef, Jr., eds.). Academic Press, San Diego, California.

Dugatkin, L.A. 1996b. Interface between culturally based preferences and genetic preferences: Female mate choice in Poecilia reticulata. Proceedings of the National Academy of Sciences USA 93:2770-2773.

Fisher, R.A. 1958. The Genetical Theory of Natural Selection. Second edition. Dover, New York. 291 pp.

Foelix, R.F. 1996. Biology of Spiders. Second edition. Oxford University Press, New York. 330 pp.

Freeberg, T.M. 2000. Culture and courtship in vertebrates: a review of social learning and transmission of courtship systems and mating patterns. Behavioural Processes 51:177-192.

Galef, B.G., Jr. \& D.J. White. 2000. Evidence of social effects on mate choice in vertebrates. Behavioural Processes 51:167-175.

Gong, A. \& R.M. Gibson. 1996. Reversal of a female preference after visual exposure to a predator in the guppy, Poecilia reticulata. Animal Behaviour 52:1007-1015.

Hauber, M.E., S.A. Russo \& P.W. Sherman. 2001. A password for species recognition in a broodparasitic bird. Proceedings of the Royal Society of London Series B-Biological Sciences 268: 1041-1048.

Hebets, E.A. 2002. Evolution and function of complex signaling in spider courtship behavior. Ecology and evolutionary biology. PhD dissertation. University of Arizona, Tucson, Arizona.

Hebets, E.A. 2003. Subadult experience influences adult mate choice in an arthropod: exposed female wolf spiders prefer males of a familiar phenotype. Proceedings of the National Academy of Sciences USA 100:13390-13395.

Hebets, E.A. 2005. Attention-altering signal interactions in the multimodal courtship display of the wolf spider Schizocosa uetzi. Behavioral Ecology 16:75-82.

Hebets, E.A. \& G.W. Uetz. 1999. Female responses to isolated signals from multimodal male courtship displays in the wolf spider genus Schizocosa (Araneae, Lycosidae). Animal Behaviour 57:86872.

Immelmann, K. 1975. Ecological significance of imprinting and early learning. Annual Review of Ecology and Systematics 6:15-37.

Irwin, D.E. \& T. Price. 1999. Sexual imprinting, learning and speciation. Heredity 82:34-354.

Kendrick, K.M., M.R. Hinton, K. Atkins, M.A. Haupt \& J.D. Skinner. 1998. Mothers determine sexual preferences. Nature 395:229-230.

Laland, K.N. 1994. On the evolutionary consequences of sexual imprinting. Evolution 48:477489.

Owens, I.P.F., C. Rowe \& A.L.R Thomas. 1999. Sexual selection, speciation and imprinting: separating the sheep from the goats. Trends in Ecology \& Evolution 14:131-132.

Penn, D. \& W. Potts. 1998. MHC-disassortative mating preferences reversed by cross-fostering. Proceedings of the Royal Society of London Series B-Biological Sciences 265:1299-1306.

Rovner, J.S. 1975. Sound production by Nearctic wolf spiders: a substratum-coupled stridulatory mechanism. Science 190:1309-1310.

Rowe, C. 2002. Sound improves visual discrimination learning in avian predators. Proceedings of the Royal Society of London Series B-Biological Sciences 269:1353-1357.

Slagsvold, T., B.T. Hansen, L.E. Johannessen \& J.T. Lifjeld. 2002. Mate choice and imprinting in birds studied by cross-fostering in the wild. Proceedings of the Royal Society of London Series B-Biological Sciences 269:1449-1455.

Soha, J.A. \& P. Marler. 2000. A species-specific acoustic cue for selective song learning in the white-crowned sparrow. Animal Behaviour 60: 297-306.

Stratton, G.E. 1983. Comparison of courtship behaviors and interspecific crosses in the Schizocosa ocreata species complex (Araneae, Lycosidae). American Zoologist 23:967-967. 
Stratton, G.E. 1991. A new species of wolf spider, Schizocosa stridulans (Araneae, Lycosidae). Journal of Arachnology 19:29-39.

Stratton, G.E. 1997. A new species of Schizocosa from the southeastern USA (Araneae, Lycosidae). Journal of Arachnology 25:84-92.

Stratton, G.E. 2005. Evolution of ornamentation and courtship behavior in Schizocosa: insights from a phylogeny based on morphology (Araneae, Lycosidae). Journal of Arachnology 33: 347-376.

Stratton, G.E. \& G.W. Uetz. 1981. Acoustic communication and reproductive isolation in two species of wolf spiders. Science 214:575-577.

Stratton, G.E. \& G.W. Uetz. 1983. Communication via substratum-coupled stridulation and reproductive isolation in wolf spiders (Araneae, Lycosidae). Animal Behaviour 31:164-172.

Stratton, G.E. \& G.W. Uetz. 1986. The inheritance of courtship behavior and its role as a reproductive isolating mechanism in two species of Schizocosa wolf spiders (Araneae, Lycosidae). Evolution 40:129-141.

ten Cate, C. 1993. Sexual imprinting and song learning: two of one kind? Netherlands Journal of Zoology 43:34-45.

ten Cate, C. \& D.R. Vos. 1999. Sexual imprinting and evolutionary processes in birds: a reassessment. Advances in the Study of Animal Behaviour 28:1-31.

Uetz, G.W. \& J.A. Roberts. 2002. Multisensory cues and multimodal communication in spiders: insights from video/audio playback studies. Brain, Behavior and Evolution 59:222-230.

White, D.J. 2004. Influences of social learning on mate-choice decisions. Learning \& Behavior 32: 105-113.

White, D.J. \& B.G. Galef, Jr. 2000. 'Culture' in quail: social influences on mate choices of female Coturnix japonica. Animal Behaviour 59: 975-979.

Wiley, R.H. 1994. Errors, exaggeration, and deception in animal communication. Pp. 157-189. In Behavioral Mechanisms in Evolutionary Ecology (L.A. Real, ed.). University of Chicago Press, Chicago, Illinois.

Manuscript received 11 October 2005, revised 9 August 2006. 